\title{
Giant ovarian dermoid masked by obesity
}

\author{
B. E. MoNK \\ M.B., M.R.C.P.
}

\author{
A. J. ISAACS \\ B.M., M.R.C.P.
}

\author{
SiR RICHARD BAYLISS \\ M.D., F.R.C.P.
}

\author{
Department of Endocrinology, Westminster Hospital, Dean Ryle Street, London, S.W.I
}

\begin{abstract}
Summary
A 37-year-old female, weighing $194 \cdot 1 \mathrm{~kg}$, is described. Her gross obesity was in part due to a massive ovarian dermoid cyst weighing at least $42 \mathrm{~kg}$, which had been overlooked in the past. A dermoid tumour of this size has not previously been reported. The possible presence of cystic ovarian tumours should be considered in patients presenting with severe generalized obesity.

\section{Introduction}

Massive ovarian tumours are usually readily diagnosable by the gross abdominal distension they produce. In the presence of severe obesity, however, the diagnosis may be more difficult. A patient is described who had a giant ovarian dermoid cyst which was overlooked for many years because of her obesity. A dermoid tumour of this size has not previously been described.
\end{abstract}

\section{Case report}

A 37-year-old nulliparous female was referred for treatment of gross obesity. Menarche had occurred at 14 years, but the patient had developed persistent secondary amenorrhoea at the age of 19 , when she weighed $128 \mathrm{~kg}$. At the age of 33 years she had been admitted to another hospital for weight reduction, and by dieting lost weight from $171 \mathrm{~kg}$ to $153 \mathrm{~kg}$. Subsequently she relapsed and became increasingly disabled.

On examination she was $175 \mathrm{~cm}$ tall and weighed $194 \cdot 1 \mathrm{~kg}$. Her obesity was generalized, but the abdomen was disproportionately large and tense, and her girth measurement was the same as her height. Her right leg was chronically swollen with lymphoedema. The patient was barely able to stand unaided and had a marked lordotic posture when she did so, resembling the stance of a pregnant woman. It was this appearance that suggested the clinical diagnosis of an ovarian cyst. An ultrasound scan showed a large transonic area directly beneath the anterior abdominal wall.

Admission to hospital was precipitated by severe cellulitis of the right leg resistant to antibiotic therapy, because of the marked deterioration in her genera 5 condition it was decided to proceed to laparotomys as a life-saving measure. At operation an enormouso cyst, densely adherent to the sigmoid mesocolon, was found arising from the left ovary, and apprex $\overrightarrow{0}$ imately 40 litres of murky straw-coloured fluid were aspirated. At a second operation 2 weeks later cyst was freed from its adhesions and excised. The patient's postoperative weight was $140 \mathrm{~kg}$, and hers mobility was greatly improved.

The decompressed cyst was $25 \mathrm{~cm}$ in diameter $\frac{\mathscr{O}}{\circ}$ The solid material weighed $2 \mathrm{~kg}$ which together with? its fluid content gives an estimated weight for thes intact tumour of at least $42 \mathrm{~kg}$. Histology showed a dermoid tumour containing hair follicles and thyroid tissue in its wall.

\section{Discussion}

There are a number of reports of massive ovarian tumours, but neglected cases are nowadays un common, although they still occur as in the case of a을 mucinous papillary cystadenocarcinoma weighing $90 \mathrm{~kg}$ (Symmonds, Spraitz and Koelsche, 1963). Such tumours are usually cystadenomas or cystadenocar $\frac{7}{8}$ cinomas (Beacham et al., 1971), and there is at. substantial mortality associated with their excision $N_{\sigma}$ Giant dermoid tumours are rare, the largest previ ously reported weighing $7 \mathrm{~kg}$ (Chalmers and Kurrein 1961).

Massive ovarian tumours usually present with obvious abdominal distension, but in the presence of severe obesity this may be overlooked (Berkowitz 1976). Investigations may be of limited value in this situation. In the present patient, plain abdomina $5_{5}^{\circ}$ $\mathrm{X}$-rays were unhelpful; her girth was too great tod 
allow access to a body-scanning machine, and from the ultrasound examination only tentative confirmation of the clinical diagnosis could be made.

Clinical awareness is therefore essential if such large tumours are not to be overlooked in obese subjects. A lordotic posture, lymphoedema of the legs, and the disproportionate size of the abdomen may, as in this case, be suggestive features.

\section{Acknowledgments}

We should like to express our thanks to Mr Roger de Vere for his invaluable help in the management of this patient.

\section{References}

Beacham, W.D., Webster, H.D., Lawson, E.H. \& Roth, L.M. (1971) Uterine and/or ovarian tumors weighing 25 pounds or more. American Journal of Obstetrics and Gynecology, 109, 1153.

BERKowitz, R. (1976) Massive ovarian enlargement in an obese patient. Obstetrics and Gynecology, 48, 483.

Chalmers, J. \& Kurrein, F. (1961) A giant dermoid cyst. Journal of Obstetrics and Gynaecology of the British Commonwealth, 68, 315.

Symmonds, R., Spraitz, A. \& Koelsche, G. (1963) Large ovarian tumor, report of a case. Obstetrics and Gynecology, $22,473$. 